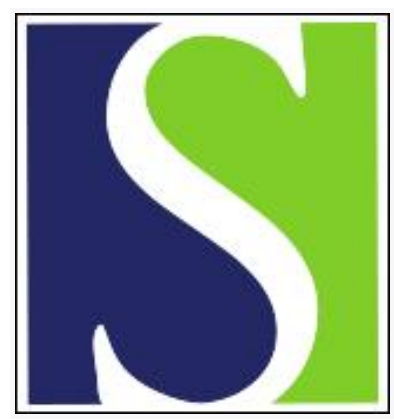

Scand J Work Environ Health 2016;42(3):228-236

https://doi.org/10.5271/sjweh.3555

Published online: 25 Feb 2016, Issue date: 01 May 2016

The association between job stress and leisure-time physical inactivity adjusted for individual attributes: evidence from a Japanese occupational cohort survey

by Oshio T, Tsutsumi A, Inoue A

Job stress, especially high job strain and effort-reward imbalance, was modestly associated with increased risk of physical inactivity, even after controlling for individual time-invariant attributes. Low job control and low reward amplified the association of physical inactivity with high job demands and high effort, respectively. Policy support is needed to support physical activity among workers facing job stress.

Refers to the following text of the Journal: 1994;20(5):349-363

The following article refers to this text: 2021;47(6):425-434

Key terms: cohort study; cohort survey; effort-reward imbalance; ERI; fixed-effects model; Japan; job strain; job stress; leisure-time physical inactivity; physical inactivity

This article in PubMed: www.ncbi.nlm.nih.gov/pubmed/26913937 


\title{
The association between job stress and leisure-time physical inactivity adjusted for individual attributes: evidence from a Japanese occupational cohort survey
}

\author{
By Takashi Oshio, PhD, ${ }^{1}$ Akizumi Tsutsumi, MD, ${ }^{2}$ Akiomi Inoue, $P h D^{3}$
}

\begin{abstract}
Oshio T, Tsutsumi A, Inoue A. The association between job stress and leisure-time physical inactivity adjusted for individual attributes: evidence from a Japanese occupational cohort survey. Scand J Work Environ Health. 2016;42(3):228-236. doi:10.5271/sjweh.3555
\end{abstract}

\begin{abstract}
Objective We examined the association between job stress and leisure-time physical inactivity, adjusting for individual time-invariant attributes.

Methods We used data from a Japanese occupational cohort survey, which included 31025 observations of 9871 individuals. Focusing on the evolution of job stress and leisure-time physical inactivity within the same individual over time, we employed fixed-effects logistic models to examine the association between job stress and leisure-time physical inactivity. We compared the results with those in pooled cross-sectional models and fixed-effects ordered logistic models.

Results Fixed-effects models showed that the odds ratio (OR) of physical inactivity were $22 \%$ higher for those with high strain jobs [high demands/low control; OR 1.22, 95\% confidence interval (95\% CI) $1.03-1.43$ ] and $17 \%$ higher for those with active jobs (high demands/high control; OR 1.17, 95\% CI 1.02-1.34) than those with low strain jobs (low demands/high control). The models also showed that the odds of physical inactivity were $28 \%$ higher for those with high effort/low reward jobs (OR 1.28, 95\% CI 1.10-1.50) and 24\% higher for those with high effort/high reward jobs (OR 1.24, 95\% CI 1.07-1.43) than those with low effort/high reward jobs. Fixed-effects ordered logistic models led to similar results.
\end{abstract}

Conclusion Job stress, especially high job strain and effort-reward imbalance, was modestly associated with higher risks of physical inactivity, even after controlling for individual time-invariant attributes.

Key terms cohort study; effort-reward imbalance; ERI; fixed-effects model; Japan; job strain.

It is widely known that leisure-time physical inactivity is a major risk factor for chronic disease, morbidity, and other health outcomes. However, the reduction in a sedentary lifestyle has been modest in advanced countries (1-4). Meanwhile, studies have suggested that exposure to job stress can be a potential contributor to leisuretime physical inactivity, as well as to other health-risk behaviors (5-12). It can be hypothesized that job stress may result in fatigue as well as general passivity and apathy, which may spill over to leisure time and impede the implementation of exercise intentions, increasing the likelihood of physical inactivity in leisure time (6,
$13,14)$. Hence, a further understanding of the association between job stress and physical inactivity can help design policy strategies to enhance workers' health.

The job demands-control (JDC) model focuses on the interaction of job demands and control as a key determinant of workers' health outcomes (15). Based on this model, it is reasonable to predict that high strain jobs, which are characterized by high demands and low control, would result in increased risks of physical inactivity. The effort-reward imbalance (ERI) model may also have implications for physical inactivity since it argues that an imbalance between higher effort spent on

\footnotetext{
${ }^{1}$ Institute of Economic Research, Hitotsubashi University, Tokyo, Japan.

2 Department of Public Health, Kitasato University School of Medicine, Kanagawa, Japan.

3 Department of Mental Health, Institute of Industrial Ecological Sciences, University of Occupational \& Environmental Health, Japan, Fukuoka, Japan.
} 
work and lower reward obtained from it has a stressful impact on workers (16). Based on the JDC and/or ERI models, an increasing number of studies have examined the association between job stress and physical inactivity (5-12, 17-19). However, the results have been generally inconclusive; some studies have provided evidence supportive of a positive, albeit modest, association between job stress and physical inactivity (5-12), while others have been skeptical of such an association (17-20).

One potential reason for these mixed results may be that most preceding studies have relied on a crosssectional analysis of the data $(5,8,10,11,17-20)$. Job stress is usually measured based on the respondent's self-reported evaluations of workplace characteristics, which are most likely affected by individual attributes in addition to objective workplace characteristics. Physical inactivity is also likely affected by individual attributes; for instance, several studies have identified some aspects of personality traits as physical activity correlates (21).

A key limitation of a cross-sectional analysis is that its estimation results cannot be free from biases related to unobserved time-invariant confounders. Although cross-sectional analysis can control for observed timeinvariant confounders (such as gender and educational attainment), it cannot control for unobserved ones (such as personality traits and other inherent individual characteristics, chronic disease, and experience in childhood). This is most likely to lead to biased estimation results. For example, if individuals with a certain unobserved attribute (such as high neuroticism) tend to feel more job stress than others, the observed association between job stress and physical inactivity in a cross-sectional analysis may reflect the association of physical inactivity with that individual attribute, rather than job stress per se.

A conventional method to overcome these problems is to employ the fixed-effects method for analysis, which focuses on within-individual variations (22-25). This method enables us to obtain unbiased estimators by controlling for individual time-invariant attributes - that is, fixed effects - both observed and unobserved. A key focus is on whether the association, which is observed in a cross-sectional analysis, remains significant even after controlling for time-invariant attributes in a fixedeffects analysis. An increasing number of studies have been employing the fixed-effects regression method to examine the determinants of mental health and other health variables (23-25). To the best of our knowledge, however, there have been few attempts to apply this method to examine the association between job stress and physical inactivity, with the notable exception of Kouvonen et al's work (12).

In the present study, we focused on the evolution of job stress and leisure-time physical inactivity within the same individual over time, using longitudinal data obtained from an occupational Japanese cohort survey.
Explicitly, we employed fixed-effects logistic models to examine the association between job stress and leisuretime physical inactivity, controlling for individual timeinvariant attributes. Based on Kouvonen et al's work (12), we considered both the JDC and ERI models. We further investigated how each demands-control and effort-reward combination was associated with physical inactivity. Some previous studies have compared the associations with physical inactivity across job demands-control combinations $(6,8,9,11,17,18$, 20 ), but effort-reward combinations have rarely been analyzed. This method allowed us to assess the relative importance of each job stress aspect as physical inactivity correlates. Moreover, our dataset, which contained data from 2-4 waves, allowed us to obtain more reliable information about the association between job stress and physical inactivity. This was as compared to previous cohort studies, most of which compared data at the baseline and one follow-up time only $(6,9)$.

\section{Methods}

\section{Study sample}

We used panel data from four survey waves of an occupational cohort study on social class and health in Japan (Japanese Study of Health, Occupation, and Psychosocial Factors Related Equity or J-HOPE). The first wave was conducted from October 2010 to December 2011; following waves were conducted approximately one year after the previous one. Data were collected from annual worksite health check-ups, which are mandatory for all Japanese employees. The recruitment periods varied among the study sites; the health check-ups were conducted in a fixed month every year, for all employees, in each employee's birth month.

The study population consisted of employees working for 13 firms, 3 of which participated only in the first three waves. The surveyed firms covered 12 industries, while the surveyed respondents were classified into nine occupation types. The original sample consisted of $10753,11405,10977$, and 6553 respondents in the first to the fourth waves, respectively (response rates: $77.0 \%$, $81.7 \%, 78.6 \%$, and $67.0 \%$, respectively). The original dataset included 39683 observations of 14140 individuals (10 550 men and 3590 women), who joined at least one wave. The attrition rates were $18.3 \%, 13.2 \%$, and $16.5 \%$ in the second, third, and fourth waves, respectively. The respondents were aged $18-76$ years [mean 41.5 (SD 10.3) years].

To compare cross-sectional and fixed-effects models, we focused on individuals who joined at least two consecutive waves. Excluding respondents with missing 
job stress indicators and other important variables, we utilized 31025 observations of 9871 individuals (7593 men and 2285 women; $78.2 \%$ of the original sample observations; $69.8 \%$ of the original sample individuals). Among these, 3382 joined all four waves, and 5020 and 1469 joined only three and two waves, respectively. The present analysis was conducted with the J-HOPE dataset as of 22 August 2014.

\section{Measures}

Physical inactivity. J-HOPE asked the respondents to report their leisure-time physical activity on a 4-point scale: (i) none; (ii) low (ie, mild exercise without breathlessness or heart palpitations) $\geq 1 /$ week; (iii) intense (ie, heavy exercise with breathlessness, heart palpitation, or sweating for $\geq 20$ minutes) $1-2 /$ week; and (iv) intense physical activity $\geq 3 /$ week. Based on the definition of physical activity in previous studies (eg, 1, 2, 6, 8) we constructed a binary variable of physical inactivity by allocating one to the answer "none" and zero to the others. Alternatively, we constructed a 4-point-score categorical variable of physical inactivity measured on a 4-point scale by reversing the order $(4=$ none to $1=$ intense physical activity $\geq 3$ /week), rather than setting up a single cut off score for physical inactivity. These selfreported responses could not be directly converted into metabolic equivalent tasks (MET). Hence, we estimated regression models to explain each of 11 health-risk factors (see the section on health-risk factors) by the above-defined binary variable of physical inactivity, to assess its relevance to workers' health.

Job demands and control. We utilized the items investigating job demands and control from the Japanese version of the Job Content Questionnaire (JCQ). The JCQ is based on the JDC model, and includes scales related to job demands (five items) and job control (nine items) rated on a 4 -point scale ( $1=$ strongly disagree to $4=$ strongly agree) (25). The internal consistency, reliability, and validity of the Japanese version of the JCQ are acceptable (26). In the present sample, we summed the responses to these items into single indices of job demands (range: 12-48) and control (range: 24-96), based on the standardized formulae $(26,27)$. We then used the study-specific median scores as cut-off points for high and low demands, and high and low job control. Finally, we categorized four job types: 1) low demands and high control (low strain); 2) high demands and high control (active); 3) low demands and low control (passive); and 4) high demands and low control (high strain) (28).

Extrinsic effort and reward. To assess effort and reward, we utilized the data collected from a simplified Japanese version of the Effort-Reward Imbalance Questionnaire
(ERIQ). The ERIQ was developed based on the ERI model (29). Its Japanese version and that of the simplified ERIQ (30) used in the present study have acceptable internal consistency, reliability, and validity scores $(31,32)$. The simplified version includes sub-scales for extrinsic effort (three items) and reward (seven items) rated on a 4-point scale (1=strongly disagree to $4=$ strongly agree). We summed the responses into single indices for effort (range: $3-12$ ) and reward (range: $7-28)$, based on the standardized formulae (30-32). We then used the study-specific median scores as cut-off points for high and low effort and high and low reward. Finally, we categorized four job types: (i) low effort/high reward, (ii) high effort/high reward, (iii) low effort/low reward, and (iv) high effort/low reward.

Health-risk factors. We considered 11 health-risk factors including psychological distress. The data were collected from annual worksite health check-ups; the K6 score (33) was an indicator of psychological distress, constructed from the survey responses. The ten healthrisk factors included systolic blood pressure, diastolic blood pressure, triglyceride level, total cholesterol level, high-density lipoprotein (HDL) cholesterol level, lowdensity lipoprotein (LDL) cholesterol level, fasting blood sugar level, hemoglobin A1c (HbA1c) level, body mass index (BMI), and waist circumstance.

To construct the K6 score, we first obtained the respondents' assessments of psychological distress using a 6-item psychological distress questionnaire: "During the past 30 days, about how often did you feel a) nervous, b) hopeless, c) restless or fidgety, d) so depressed that nothing could cheer you up, e) that everything needed added effort, and f) was worthless?"; responses were rated on a 5 -point scale $(0=$ none of the time to $4=$ all of the time). We then calculated the sum of the reported scores (range: 0-24) and defined it as the K6 score. Higher K6 scores reflect higher levels of psychological distress. Its reliability and validity have been demonstrated on a Japanese sample $(34,35)$.

\section{Covariates}

We used both individual time-invariant and -variant variables as covariates. For individual time-invariant variables, we used gender, educational attainment (high school or below, junior college, college, and graduate school), and 13 firm indicators. Among individual time-variant variables, the most important one was hours worked per week. As suggested by preceding studies $(36,37)$, longer hours worked are expected to restrain physical inactivity through reduced leisure time, regardless of workplace stress. The survey asked the respondents to choose from five groups related to hours worked per week $(\leq 30,31-40,41-50,51-60$, and $\geq 61$ 
hours). For simplicity, we assumed 20, 35, 45, 55, and 65 hours for each bracket and used them as scores of a continuous variable of hours worked. In addition, we considered nine job types (such as manager, clerk, and factory worker), six income brackets $(\leq 2.99,3-4.99$, $5-7.99,8-9.99,10-14.99$, and $\geq 15$ million yen), and age $(<30,30 \mathrm{~s}, 40 \mathrm{~s}, 50 \mathrm{~s}$, and $\geq 60$ years or above $)$ as individual time-variant variables. We also included indicator variables of the four waves to control for wave-specific factors.

\section{Statistical analysis}

After descriptive analysis, which aimed at summarizing the basic features of each aspect of job stress, we conducted three analyses. First, we assessed the relevance of physical inactivity in workers' health, by estimating linear regression models to explain the 11 health-risk factor variables by physical inactivity along with covariates. This analysis was needed because our physical inactivity measure was based on the respondent's self-assessments and its relevance in workers' health was not necessarily warranted. Second, as a main analysis, we examined the association between job stress and physical inactivity. Specifically, we estimated physical inactivity by three job types - high demands/high control (active), low demands/low control (passive), and high demands/low control (high strain) - considering low demands/high control (low strain) as a reference, based on the JDC model. We also estimated an ERI version of this model, with high effort/high reward, low effort/low reward, and high effort/low reward as regressors, and low effort/high reward as a reference. In these models, we used a binary variable of physical inactivity and employed logistic regression models. Finally, we examined the robustness of the results of these logistic models. To this end, we replaced a binary variable of physical inactivity with its 4-point categorical variable described earlier and estimated ordered logistic models to explain physical inactivity by the same regressors used in the logistic models.

In all of these regression analyses, we employed fixed-effects models in order to control for individual time-invariant attributes, whether observed or unobserved. To enable explanation of each health-risk variable, which was a continuous variable, using the above models, we regressed each mean-centered health-risk variable on all mean-centered regressors (22). For the logistic fixed-effects models in the second analysis, we used the maximum likelihood estimation conditional on the sum of events (ie, the amount of physical inactivity during the waves), which provided unbiased estimators (38). For the ordered logistic fixed-effects models, we employed a recently developed method (39), which provided unbiased estimators as in the case of logistic fixed-effects models. For both logistic and ordered logistic models, respondents who stayed in the same physical activity status were automatically dropped from the analysis, because these models concentrated on within-individual variations. For all of these fixedeffects models, we compared their results with those in pooled cross-sectional models to assess the importance of controlling for individual time-invariant attributes.

\section{Results}

Table 1 summarizes basic characteristics of respondents at baseline, showing that 3741 (35.1\%) of the respondents were physically inactive in leisure time. Women were less active than men. Educational attainment and income were positively associated with physical activity, while smoking was negatively associated with it. We controlled for these factors in the regression analysis.

The key features of the four job stress variables are presented in table 2 in terms of (i) the ranges, means, and standard deviations of their scores, (ii) pairwise correlations with each other, and (iii) prevalence of physical inactivity by their high and low levels. This table shows high correlations between job demands and effort (0.617) and between job control and reward (0.345), suggesting that these pairs of concepts - as well as the two models of job stress (JDC and ERI models) - potentially overlap with each other, respectively. This table also shows that the prevalence of physical inactivity was positively associated with high job demands, low job control, high effort, and low reward, suggesting that each aspect of job stress was independently associated with physical inactivity. In addition, the prevalence of physical inactivity was very close between high job demands and high effort, and

Table 1. Basic characteristics of the respondents at baseline. ${ }^{2}$

\begin{tabular}{|c|c|c|c|c|c|c|c|c|c|}
\hline & \multicolumn{3}{|c|}{$\begin{array}{c}\text { All } \\
(\mathrm{N}=9871)\end{array}$} & \multicolumn{3}{|c|}{$\begin{array}{l}\text { Physically active } \\
\qquad(\mathrm{N}=3741)\end{array}$} & \multicolumn{3}{|c|}{$\begin{array}{l}\text { Physically inactive } \\
\qquad(\mathrm{N}=6130)\end{array}$} \\
\hline & $\%$ & Mean & $\overline{S D}$ & $\%$ & Mean & $\overline{S D}$ & $\%$ & Mean & SD \\
\hline Men & 76.9 & & & 83. & & & 72.9 & & \\
\hline Women & 23.1 & & & 16. & & & 27.1 & & \\
\hline $\begin{array}{l}\text { Education } \\
\text { High school } \\
\text { or less }\end{array}$ & 39.2 & & & 36. & & & 41.0 & & \\
\hline Junior college & 16.3 & & & 13. & & & 18.0 & & \\
\hline College & 33.8 & & & 37. & & & 31.3 & & \\
\hline $\begin{array}{l}\text { Graduate } \\
\text { school }\end{array}$ & 10.6 & & & 12.2 & & & 9.6 & & \\
\hline Smoking & 28.4 & & & 25.7 & & & 30.1 & & \\
\hline Age (years) & & 40.3 & 10.4 & & 41.0 & 10.6 & & 39.9 & 10.3 \\
\hline $\begin{array}{l}\text { Income } \\
\text { ( } ¥ \text { million/year) }\end{array}$ & & 6.9 & 3.5 & & 7.3 & 3.5 & & 6.7 & 3.3 \\
\hline $\begin{array}{l}\text { Hours worked } \\
\text { per week }\end{array}$ & & 41.9 & 11.0 & & 42.3 & 10.1 & & 41.6 & 11.5 \\
\hline
\end{tabular}


between low job control and low reward, again suggesting that they overlap with each other.

Table 3 summarizes the results of the regression models that examined the association between physical inactivity and each health-risk factor. It reveals that physical inactivity was associated with most of the healthrisk factors. The fixed-effects models (right columns) show that physical inactivity was positively associated with systolic and diastolic blood pressure, triglyceride level, LDL cholesterol level, fasting blood glucose level, HbAlc level, BMI, waist circumference, and K6 scores. On comparison, the pooled cross-sectional models (center columns) failed to show a significant association of physical inactivity with systolic blood pressure, LDL cholesterol level, and HbAlc level at 5\% significance, and showed a negative relationship with BMI.

Table 4 shows how the estimated associations between job stress and physical inactivity differed between the pooled cross-sectional and fixed-effects logistic models for JDC (top section) and ERI (bottom section), respectively. The number of respondents in the fixed-effects logistic models was 3047 , which was $30.9 \%$ of that in the pooled cross-sectional models, because those who stayed physically active or inactive were removed from the fixed-effects logistic models.

For the JDC model, the pooled cross-sectional models indicated that all job stress types raised the odds of physical inactivity compared to low demands/high control (ie, low strain) jobs. The odds ratio (OR) was highest for high demands/low control (ie, high strain) jobs, followed by low demands/low control (ie, passive) jobs and then high demands/high control (ie, active) jobs. In the fixed-effects logistic models, the association between low demands/low control jobs and physical inactivity became non-significant at $5 \%$ significance. Meanwhile, both high demands/low control and high demands/high control jobs remained modestly associated with the increased risk of physical inactivity.

In the ERI model, all types of job stress raised the odds of physical inactivity compared to low effort/high reward jobs in pooled cross-sectional models. However, the OR of low effort/low reward jobs was lower than

Table 2. Key features of job stress: pooled data ( $N=31025)$. [SD=standard deviation.]

\begin{tabular}{|c|c|c|c|c|c|c|c|c|c|}
\hline & \multicolumn{3}{|c|}{ Score } & \multicolumn{3}{|c|}{ Pairwise correlation a with: } & \multicolumn{3}{|c|}{ Prevalence of physical inactivity (\%) } \\
\hline & Range & Mean & SD & $\begin{array}{c}\text { Job } \\
\text { demands }\end{array}$ & $\begin{array}{c}\text { Job } \\
\text { control }\end{array}$ & Effort & $\operatorname{High}(\mathrm{A})$ & Low (B) & $\begin{array}{c}\text { Difference } \\
(A-B)^{b}\end{array}$ \\
\hline Job demands & $12-48$ & 33.0 & 5.4 & & & & 61.7 & 58.9 & 2.8 \\
\hline Job control & $24-96$ & 66.3 & 9.9 & 0.210 & & & 57.4 & 63.6 & -6.2 \\
\hline Effort & $3-12$ & 8.0 & 1.8 & 0.617 & 0.167 & & 61.7 & 58.3 & 3.5 \\
\hline Reward & $7-28$ & 18.2 & 3.0 & -0.106 & 0.345 & -0.114 & 57.9 & 63 & -5.1 \\
\hline
\end{tabular}

a All significantly $(P<0.001)$ different from 0 .

${ }^{\mathrm{b}}$ All significantly $(P<0.001)$ different from 0 .

Table 3. The estimated association between physical inactivity and health-risk factors: pooled cross-sectional and fixed-effects models. Controlled for gender, educational attainment, hours worked, income, job types, age, and waves. [SE=standard error; HDL=high density lipoprotein; LDL=low density lipoprotein; HbA1c=hemoglobin A1c; BMI=body mass index]

\begin{tabular}{|c|c|c|c|c|c|c|}
\hline & \multicolumn{3}{|c|}{ Pooled cross-sectional } & \multicolumn{3}{|c|}{ Fixed-effects } \\
\hline & $\begin{array}{c}\text { Difference a }^{\text {a }} \\
\%\end{array}$ & $\begin{array}{c}\text { SE/mean } \\
\%\end{array}$ & $\begin{array}{c}\text { Observations } \\
\mathrm{N}\end{array}$ & $\begin{array}{c}\text { Difference a /mean } \\
\%\end{array}$ & $\begin{array}{c}\text { SE/mean } \\
\%\end{array}$ & $\begin{array}{c}\text { Observations } \\
\mathrm{N}\end{array}$ \\
\hline Systolic blood pressure (mmHg) & $0.25^{b}$ & 0.14 & 29140 & $0.38^{c}$ & 0.17 & 9708 \\
\hline Diastolic blood pressure $(\mathrm{mmHg})$ & $0.48^{d}$ & 0.17 & 29141 & $0.55^{d}$ & 0.21 & 9708 \\
\hline Triglyceride level (mg/dL) & $3.74^{e}$ & 1.06 & 26584 & $2.98^{c}$ & 1.36 & 9192 \\
\hline Total cholesterol level (mg/dL) & 0.24 & 0.33 & 10105 & 0.45 & 0.36 & 4261 \\
\hline HDL cholesterol level (mg/dL) & -2.46 e & 0.30 & 27175 & -0.36 & 0.24 & 9430 \\
\hline LDL cholesterol level (mg/dL) & $0.56^{b}$ & 0.31 & 27062 & $0.86^{d}$ & 0.30 & 9337 \\
\hline Fasting blood glucose level (mg/dL) & 1.27 e & 0.28 & 15590 & $0.78^{c}$ & 0.32 & 5744 \\
\hline HbA1c level (\%) & 0.25 & 0.16 & 23759 & $0.57^{e}$ & 0.17 & 8404 \\
\hline $\mathrm{BMI}\left(\mathrm{kg} / \mathrm{m}^{2}\right)$ & $-0.81^{d}$ & 0.27 & 12373 & $0.37^{d}$ & 0.11 & 6103 \\
\hline Waist circumstance $(\mathrm{cm})$ & $0.80^{e}$ & 0.15 & 22333 & $0.42^{e}$ & 0.08 & 8507 \\
\hline K6 scores & $11.19 \mathrm{e}$ & 1.04 & 30974 & $8.87^{\text {e }}$ & 1.22 & 9744 \\
\hline
\end{tabular}

a Difference in the value of each health-risk factor for those with physical inactivity compared to others, in terms of the ratio to the sample mean.

b Marginally significantly $(P<0.1)$ different from 0 .

c Significantly $(\mathrm{P}<0.05)$ different from 0 .

d Significantly $(P<0.01)$ different from 0 .

e Significantly $(\mathrm{P}<0.001)$ different from 0 . 
Table 4. Estimated association between job stress and physical inactivity: pooled logistic and fixed-effects logistic models. ${ }^{a}$ [OR=odds ratio, $95 \% \mathrm{Cl}=95 \%$ confidence interval]

\begin{tabular}{|c|c|c|c|c|}
\hline & \multicolumn{2}{|c|}{$\begin{array}{c}\text { Pooled cross- } \\
\text { sectional } \\
(\mathrm{N}=31025 / 9871)\end{array}$} & \multicolumn{2}{|c|}{$\begin{array}{c}\text { Fixed-effects } \\
(\mathrm{N}=10135 / 3047)\end{array}$} \\
\hline & $\mathrm{OR}$ & $95 \% \mathrm{Cl}$ & $\mathrm{OR}$ & $95 \% \mathrm{Cl}$ \\
\hline \multicolumn{5}{|l|}{ Job demands-control models } \\
\hline $\begin{array}{l}\text { Low demands/high control } \\
\text { (low strain) }\end{array}$ & 1.00 & & 1.00 & \\
\hline $\begin{array}{l}\text { High demands/high control } \\
\text { (active) }\end{array}$ & $1.12^{\mathrm{c}}$ & $1.05-1.20$ & $1.17^{\mathrm{d}}$ & $1.02-1.34$ \\
\hline $\begin{array}{l}\text { Low demands/low control } \\
\text { (passive) }\end{array}$ & $1.20^{c}$ & $1.11-1.28$ & 1.09 & $0.93-1.28$ \\
\hline $\begin{array}{l}\text { High demands/low control } \\
\text { (high strain) }\end{array}$ & $1.33^{c}$ & $1.24-1.43$ & $1.22^{d}$ & $1.03-1.43$ \\
\hline \multicolumn{5}{|l|}{ ERI models } \\
\hline Low effort/high reward & 1.00 & & 1.00 & \\
\hline High effort/high reward & $1.19^{c}$ & $1.12-1.27$ & $1.24^{e}$ & $1.07-1.43$ \\
\hline Low effort/low reward & $1.16^{c}$ & $1.07-1.25$ & 0.99 & $0.84-1.17$ \\
\hline High effort/low reward & $1.29 c$ & $1.21-1.38$ & $1.28^{\mathrm{e}}$ & $1.10-1.50$ \\
\hline $\begin{array}{l}\text { a Controlled for gender, educati } \\
\text { job types, age, and waves. } \\
\text { b Number observations / numb } \\
\text { ' Significantly }(P<0.001) \text { differe } \\
\text { d Significantly }(P<0.05) \text { differen } \\
\text { e Significantly }(P<0.01) \text { differen }\end{array}$ & $\begin{array}{l}\text { al attain } \\
\text { individu } \\
\text { from } 1 . \\
\text { from } 1.0\end{array}$ & $\begin{array}{l}\text { ment, hours } \\
\text { als. } \\
00 \text {. } \\
0 .\end{array}$ & worked, & income, \\
\hline
\end{tabular}

those of the other two types of job categories. Meanwhile, fixed-effects logistic models show that low effort/ low reward jobs had no significant association with physical inactivity, while both high effort/low reward and high effort/high reward jobs remained modestly associated with the increased risk of physical inactivity. This pattern of results was similar to that for the JDC model, with job demands and control replaced by effort and reward, respectively. This probably reflects overlapping aspects between job demands and effort, between job control and reward, and correspondingly between the JDC and ERI models, as already suggested by table 2 .

Finally, table 5 provides the results of the employed ordered logistic models to predict a 4-point categorical variable of physical inactivity. The number of respondents was larger than that in the logistic model presented in table 4 because fewer respondents stayed in one of four physical activity statuses as compared to those who exhibited one of two physical activity levels (active or inactive). The OR in this table indicates how each job stress raised the odds of a reduction in the physical activity level, assuming that the OR was the same across the levels of physical inactivity. Evidently, these results are similar to those presented in table 4, in terms of OR magnitude for each type of job stress, as well as regarding its order and statistical significance, indicating the robustness of the results obtained from the fixed-effects logistic models.
Table 5. Estimated association between job stress and physical inactivity (measured on a four-point scale): pooled ordered logistic and fixed-effects ordered logistic models. ${ }^{\text {a }}$ [OR=odds ratio, 95\% $\mathrm{Cl}=95 \%$ confidence interval]

\begin{tabular}{|c|c|c|c|c|}
\hline & \multicolumn{2}{|c|}{$\begin{array}{c}\text { Pooled cross- } \\
\text { sectional } \\
(\mathrm{N}=31025 / 9871)\end{array}$} & \multicolumn{2}{|c|}{$\begin{array}{c}\text { Fixed-effects } \\
(\mathrm{N}=18459 / 4178)\end{array}$} \\
\hline & $\mathrm{OR}$ & $95 \% \mathrm{Cl}$ & $\mathrm{OR}$ & $95 \% \mathrm{Cl}$ \\
\hline \multicolumn{5}{|l|}{ Job demands-control models } \\
\hline $\begin{array}{l}\text { Low demands/high control } \\
\text { (low strain) }\end{array}$ & 1.00 & & 1.00 & \\
\hline $\begin{array}{l}\text { High demands/high control } \\
\text { (active) }\end{array}$ & $1.13^{c}$ & $1.06-1.21$ & $1.19 \mathrm{~d}$ & $1.06-1.35$ \\
\hline $\begin{array}{l}\text { Low demands/low control } \\
\text { (passive) }\end{array}$ & $1.20^{c}$ & $1.12-1.28$ & 1.13 & $0.98-1.30$ \\
\hline $\begin{array}{l}\text { High demands/low control } \\
\text { (high strain) }\end{array}$ & $1.35^{c}$ & $1.26-1.45$ & $1.28^{c}$ & $1.11-1.49$ \\
\hline \multicolumn{5}{|l|}{ ERI models } \\
\hline Low effort/h & 1.00 & & 1.00 & \\
\hline High & $1.20^{c}$ & $1.13-1$ & $1.27^{\mathrm{c}}$ & 1.44 \\
\hline & $1.15^{c}$ & $1.07-1.23$ & 1.01 & $0.87-1.17$ \\
\hline High effort/low reward & $1.29 \mathrm{c}$ & $1.21-1.38$ & $1.34^{c}$ & $1.17-1.55$ \\
\hline
\end{tabular}

a Controlled for gender, educational attainment, hours worked, income, job types, age, and waves.

${ }^{\mathrm{b}}$ Number observations / number individuals.

c Significantly $(P<0.001)$ different from 1.00 .

d Significantly $(P<0.01)$ different from 1.00 .

\section{Discussion}

In the current study, we investigated the association between job stress and physical inactivity based on the pooled cross-sectional and fixed-effects models. To the best of our knowledge, the current study is one of the first attempts to address this issue in a non-Western country, ie, Japan, in which the prevalence of physical inactivity was higher than that in many other countries (40).

The results obtained from our pooled cross-sectional analysis showed that job stress-especially, high job strain and ERI — was modestly associated with an increased risk of physical inactivity in leisure time. This adds to evidence supportive of a positive association between job stress and physical inactivity, which has often been observed in previous studies (5-12). Unlike the present study, Tsutsumi et al's study (19) found less significant and inconsistent associations between job characteristics and physical activity outside work, using Japanese data. As pointed out by Tsutsumi et al, it was probably because their index of physical activity outside work did not explicitly measure the intensity of leisuretime physical activity.

A more noticeable finding from the current study was that job stress was associated with increased risk of physical inactivity, even after controlling for individual time-invariant attributes in the fixed-effects logistic models. This result was also supported by the ordered fixed-effects logistic models, which confirmed that 
job stress was associated with a lower level of physical activity. These results indicate that the association between job stress and physical inactivity, albeit modest, was real, even if it tended to be overestimated in the cross-sectional models. Our findings were in line with those found in Kouvonen et al's work (12), which applied fixed-effects analysis to Finnish data.

Different results between the cross-sectional and fixed-effects models underscore the importance of controlling for individual time-invariant attributes when assessing the association between job stress and physical inactivity. Specifically, we found that the association between low demands/low control (passive) jobs and physical inactivity became non-significant in the fixedeffects model. It might be possible that individuals who preferred physical inactivity may be inactive by nature, and hence tended to choose low demands/low control jobs in the workplace. Results suggest that without controlling for such an individual attribute, we may overestimate the association between low demands/low control jobs and physical inactivity. This also seems to be true of low effort/low reward jobs, whose association with physical inactivity also became non-significant in the fixed-effects models. In addition to these key findings, we found that physical inactivity was generally associated with increased health risks, which were measured by blood pressure, cholesterol levels, BMI, and other health-risk indicators (see table 1). With these observations combined, we can tentatively argue that physical inactivity mediates the impact of job stress on workers' health. It should be noted, however, that reverse causality cannot be ruled out based on the performed analyses, and the mediation effect was not explicitly tested in the present study. These issues remain to be addressed in future research.

Another noticeable finding was that high job demands (in the JDC model) and high effort (in the ERI model) in terms of the association with physical inactivity, in line with previous studies $(10,11)$. As seen in tables 2 and 3 , high job demands raised the odds of physical inactivity, whether combined with high or low control. Similarly, high effort had a positive association with physical inactivity, whether combined with high or low reward. Meanwhile, low control and low reward are shown to have somewhat amplified the association of physical inactivity with high demands and high effort, respectively.

We acknowledge that the current study has several limitations. First, it should be noted that the fixed-effects models concentrated exclusively on within-individual variations over time. Especially in the case of the fixedeffects logit models, more than a half of the respondents who stayed active or inactive throughout waves were dropped from the analysis. This implies that the observed association between job stress and physical inactivity in the fixed-effects models - which was found to be attenuated from the pooled cross-sectional models - may be still overstated.

Second, we focused on leisure-time physical inactivity, thereby ignoring other domains of physical activity such as worktime and commuting ones. Previous studies have found that different domains of physical activity as well as their combination were differently associated with workers' health (41-43), suggesting that we have to expand the fixed-effects analysis into the examination of the association of job stress with various domains of physical activity or their combination.

Third, the current study did not identify the one-way causality from job stress to physical inactivity, even though it controlled for individual time-invariant attributes, which likely confounded their association. In particular, it is possible that the occurrence of a health problem makes employees feel that their job is more stressful and, at the same time, spend less time doing physical activity, making it difficult to determine whether the cause of physical inactivity is the health problem or the stress of work. In addition, a reverse causation from physical inactivity to job stress cannot be ruled out. A further study is required to identify causation.

In addition to these key limitations, the following points should be noted in interpreting the estimation results in the present study. First, the models did not control for unobserved variables that were time-variant even though they did control for time-invariant variables, and they did not examine how job stress duration or repeated exposure was associated with physical inactivity. Second, our study sample was not randomly selected and was heavily biased towards male workers. Hence, the results may not apply to the general Japanese working population. Finally, results were not free from biases owing to the exclusion of respondents with missing data and attrition.

Despite these limitations, we can conclude that job stress - especially in the forms of high job strain and ERI - is modestly associated with physical inactivity in leisure time. Given that physical inactivity is closely related to many health-risk factors, as confirmed in our dataset, the results of the current study underscore the need for policy efforts to reduce workplace stress exposure and support physical activity among workers experiencing job stress.

\section{Acknowledgements}

We used panel data from four survey waves of an occupational cohort study on social class and health in Japan (Japanese Study of Health, Occupation, and Psychosocial Factors Related Equity; J-HOPE), which was supported by a Grant-in-Aid for Scientific Research (KAK- 
ENHI) on Innovative Areas (Research in a Proposed Research Area) 2009-2013 (No. 4102-21119001) from the Ministry of Education, Culture, Sports, Science and Technology, Japan. The present study was financially supported by a Grant-in-Aid for Scientific Research (KAKENHI) from the Japan Society for the Promotion of Science, Grant Numbers 26253042 and 26245039.

\section{References}

1. Birdee GS, Byrne DW, McGown PW, Rothman RL, Rolando LA, Holmes MC, et al. Relationship between physical inactivity and health characteristics among participants in an employeewellness program. J Occup Environ Med. 2013;55:514-9. http://dx.doi.org/10.1097/JOM.0b013e31827f37d7

2. Borrell LN. The effects of smoking and physical inactivity on advancing mortality in U.S. adults. Ann Epidemiol. 2014;24:484-7. http://dx.doi.org/10.1016/j. annepidem.2014.02.016

3. Lee IM, Shiroma EJ, Lobelo F, Puska P, Blair SN, Katzmarzyk $\mathrm{PT}$, et al. Effect of physical inactivity on major noncommunicable diseases worldwide: an analysis of burden of disease and life expectancy. Lancet. 2012;380:219-29. http:// dx.doi.org/10.1016/S0140-6736(12)61031-9

4. World Health Organization. Global recommendations on physical activity for health. http://www.who.int/ dietphysicalactivity/publications/9789241599979/en/ (accessed 14 Sep 2015).

5. Choi B, Schnall P, Yang H, Dobson M, Landsbergis P, Israel L, et al. Psychosocial working conditions and active leisure-time physical activity in middle-aged US workers. Int J Occup Med Environ Health. 2010;23:239-53. http://dx.doi.org/10.2478/ v10001-010-0029-0

6. Fransson EI, Heikkilä K, Nyberg ST, Zins M, Westerlund H, Westerholm P, et al. Job strain as a risk factor for leisure-time physical inactivity: an individual-participant meta-analysis of up to 170,000 men and women: the IPD-Work Consortium. Am J Epidemiol. 2012;176:1078-89. http://dx.doi.org/10.1093/ aje/kws336

7. Gimeno D, Elovainio M, Jokela M, De Vogli R, Marmot MG, Kivimäki M. Association between passive jobs and low levels of leisure-time physical activity: the Whitehall II cohort study. Occup Environ Med. 2009;66:772-6. http://dx.doi. org/10.1136/oem.2008.045104

8. Griep RH, Nobre AA, Alves MG, da Fonseca Mde J, Cardoso Lde O, Giatti L, et al. Job strain and unhealthy lifestyle: results from the baseline cohort study, Brazilian Longitudinal Study of Adult Health (ELSA-Brazil). BMC Public Health. 2015;15:309. http://dx.doi.org/10.1186/s12889-015-1626-4

9. Heikkilä K, Fransson EI, Nyberg ST, Zins M, Westerlund H, Westerholm P, et al. Job Strain and health-related lifestyle: findings from an individual-participant meta-analysis of 118 000 working adults. Am J Public Health. 2013;103:2090-7.
http://dx.doi.org/10.2105/AJPH.2012.301090

10. Kouvonen A, Kivimäki M, Elovainio M, Pentti J, Linna A, Virtanen M, et al. Effort/reward imbalance and sedentary lifestyle: an observational study in a large occupational cohort. Occup Environ Med. 2006;63:422-7. http://dx.doi.org/10.1136/ oem.2005.020974

11. Kouvonen A, Kivimäki M, Elovainio M, Virtanen M, Linna A, Vahtera J. Job strain and leisure-time physical activity in female and male public sector employees. Prev Med. 2005;41:532-9. http://dx.doi.org/10.1016/j.ypmed.2005.01.004

12. Kouvonen A, Vahtera J, Oksanen $T$, Pentti J, Väänänen $A K$, Heponiemi T, et al. Chronic workplace stress and insufficient physical activity: a cohort study. Occup Environ Med. 2013;70:38. http://dx.doi.org/10.1136/oemed-2012-100808

13. Amick BC III, McDonough P, Chang H, et al. Relationship between all-cause mortality and cumulative working life course psychosocial and physical exposures in the United States labor market from 1968 to 1992. Psychosom Med. 2002;64:370-81. http://dx.doi.org/10.1097/00006842-200205000-00002

14. Payne N, Jones F, Harris P. The impact of working life on health behavior: the effect of job strain on the cognitive predictors of exercise. J Occup Health Psychol. 2002;7:342-53. http://dx.doi. org/10.1037/1076-8998.7.4.342

15. Karasek RA. Job demands, job decision latitude, and mental strain: implications for job redesign. Admin Sci Q. 1979;24:285-308. http://dx.doi.org/10.2307/2392498

16. Siegrist J. Adverse health effects of high-effort/low-reward conditions. J Occup Health Psychol. 1996;1:27-41. http://dx.doi. org/10.1037/1076-8998.1.1.27

17. Ali SM, Lindstrom M. Psychosocial work conditions, unemployment, and leisure-time physical activity: a populationbased study. Scand J Public Health. 2006; 34:209-16. http:// dx.doi.org/10.1080/14034940500307515

18. Lallukka T, Sarlio-Lähteenkorva S, Roos E, Laaksonen M, Rahkonen O, Lahelma E. Working conditions and health behaviors among employed women and men: the Helsinki Health Study. Prev Med. 2004;38:48-56. http://dx.doi.org/10.1016/j. ypmed.2003.09.027

19. Tsutsumi A, Kayaba K, Yoshimura M, Sawada M, Ishikawa $\mathrm{S}$, Sakai K, et al. Association between job characteristics and health behaviors in Japanese rural workers. Int J Behav Med. 2003;10:125-42. http://dx.doi.org/10.1207/ S15327558IJBM1002_03

20. Wemme KM, Rosvall M. Work related and non-work related stress in relation to low leisure time physical activity in a Swedish population. J Epidemiol Community Health. 2005;59:377-9. http://dx.doi.org/10.1136/jech.2004.031526

21. Rhodes RE, Smith EI. Personality correlates of physical activity: a review and meta-analysis. Br J Sports Med. 2006;40:958-65. http://dx.doi.org/10.1136/bjsm.2006.028860

22. Wooldridge J M. Econometric analysis of cross section and panel data, 2nd edition. Cambridge, MA: The MIT Press, 2010.

23. Lorant V, Croux C, Weich S, Deliège D, Mackenbach J, Ansseau M. Depression and socioeconomic risk factors: 7-year longitudinal population study. Br J Psychiatry. 2007;190:293-8. 
http://dx.doi.org/10.1192/bjp.bp.105.020040

24. McKenzie SK, Imlach Gunasekara F, Richardson K, Carter K. Do changes in socioeconomic factors lead to changes in mental health? Findings from three waves of a population based panel study. J Epidemiol Community Health. 2014;68:253-60. http:// dx.doi.org/10.1136/jech-2013-203013

25. Oshio T, Tsutsumi A, Inoue A. Do time-invariant confounders explain away the association between job stress and workers' mental health? Evidence from Japanese occupational panel data. Soc Sci Med. 2015;126:138-44. http://dx.doi. org/10.1016/j.socscimed.2014.12.021

26. Karasek RA. Job Content Questionnaire and User's Guide. Lowell, MA: University of Massachusetts at Lowell, 1985.

27. Kawakami N, Kobayashi F, Araki S, Haratani T, Furui H. Assessment of job stress dimensions based on the job demands-control model of employees of telecommunication and electric power companies in Japan: reliability and validity of the Japanese version of Job Content Questionnaire. Int J Behav Med. 1995;2:358-75. http://dx.doi.org/10.1207/ s15327558ijbm0204_5

28. Landsbergis PA, Schnall PL, Warren K, Pickering TG, Schwartz JE. Association between ambulatory blood pressure and alternative formulations of job strain. Scand J Work Environ Health. 1994;20:349-63. http://dx.doi.org/10.5271/ sjweh. 1386

29. Siegrist J, Starke D, Chandola T, Godin I, Marmot M, Niedhammer I, et al. The measurement of effort-reward imbalance at work: European comparisons. Soc Sci Med. 2004:58;1483-99. http://dx.doi.org/10.1016/S02779536(03)00351-4

30. Siegrist J, Wege N, Pühlhofer F, Wahrendorf M. A short generic measure of work stress in the era of globalization: effort-reward imbalance. Int Arch Occup Environ Health. 2009;82:1005-13. http://dx.doi.org/10.1007/s00420-008$0384-3$

31. Kurioka S, Inoue A, Tsutsumi A. Optimum cut-off point of the Japanese short version of the Effort-Reward Imbalance Questionnaire. J Occup Health. 2013;55:340-8. http://dx.doi. org/10.1539/joh.12-0235-OA

32. Tsutsumi A, Ishitake T, Peter R, Siegrist J, Matoba T. The Japanese version of the effort-reward imbalance questionnaire: a study in dental technicians. Work Stress. 2001;15:86-96. http://dx.doi.org/10.1080/02678370118173

33. Kessler RC, Andrews G, Colpe LJ, Hiripi E, Mroczek DK, Normand SL, et al. Short screening scales to monitor population prevalences and trends in non-specific psychological distress. Psychol Med. 2002;32:959-76. http://dx.doi.org/10.1017/ S0033291702006074
34. Furukawa TA, Kawakami N, Saitoh M, Ono Y, Nakane Y, Nakamura Y, et al. The performance of the Japanese version of the K6 and K10 in the World Mental Health Survey Japan. Int J Methods Psychiatr Res. 2008;17:152-8. http://dx.doi. org/10.1002/mpr.257

35. Sakurai K, Nishi A, Kondo K, Yanagida K, Kawakami N. Screening performance of K6/K10 and other screening instruments for mood and anxiety disorders in Japan. Psychiatry Clin Neurosci. 2001;65:434-41. http://dx.doi. org/10.1111/j.1440-1819.2011.02236.x

36. Kirk MA, Rhodes RE. Occupation correlates of adults' participation in leisure-time physical activity: a systematic review. Am J Prev Med. 2011;40:476-85. http://dx.doi. org/10.1016/j.amepre.2010.12.015

37. Schneider S, Becker S. Prevalence of physical activity among the working population and correlation with work-related factors: results from the first German National Health Survey. J Occup Health. 2005;47:414-23. http://dx.doi.org/10.1539/ joh. 47.414

38. Chamberlain G. Analysis of covariance with qualitative data. Rev Econ Stud. 1980;47:225-38. http://dx.doi. org/10.2307/2297110

39. Baetschmann G, Staub KE, Winkelmann R. Consistent estimation of the fixed effects ordered logit model. J R Stat Soc Ser A Stat Soc. 2015;178:685-703. http://dx.doi.org/10.1111/ rssa. 12090

40. Bauman A, Bull F, Chey T, Craig CL, Ainsworth BE, Sallis JF, et al. The International prevalence study on physical activity: results from 20 countries. Int J Behav Nutr Phys Act. 2009;6:21. http://dx.doi.org/10.1186/1479-5868-6-21

41. Kuwahara K, Honda T, Nakagawa T, Yamamoto S, Akter S, Hayashi T, et al. Associations of leisure-time, occupational, and commuting physical activity with risk of depressive symptoms among Japanese workers: a cohort study. Int J Behav Nutr Phys Act. 2015;12:119. http://dx.doi.org/10.1186/ s12966-015-0283-4

42. Mammen G, Faulkner G. Physical activity and the prevention of depression: a systematic review of prospective studies. Am J Prev Med. 2013;45:649-57. http://dx.doi.org/10.1016/j. amepre.2013.08.001

43. Samitz G, Egger M, Zwahlen M. Domains of physical activity and all-cause mortality: systematic review and doseresponse meta-analysis of cohort studies. Int $\mathrm{J}$ Epidemiol. 2011;40:1382-400. http://dx.doi.org/10.1093/ije/dyr112

Received for publication: 9 October 2015 